\title{
Using seismicity and tomographic imaging to infer the location and rupture of the reservoir that supplies magma to the 2021 eruption at Fagradalsfjall, Iceland
}

\section{Authors}

\author{
Alex Hobé1, Burcu Selek', Mohsen Bazargan', Ari Tryggvason¹, Agust Gudmundsson² \\ ${ }^{1}$ Department of Earth Science, Uppsala University, Uppsala, Sweden \\ 2 Department of Earth Sciences, Royal Holloway University of London, Egham, UK
}

\section{Abstract}

Although many deep-seated magma reservoirs have been detected beneath active volcanic systems in Iceland in recent decades, none were detected beneath the 5 volcanic systems on the Reykjanes Peninsula (RP) before the year 2020. This area, close to Iceland's capital Reykjavik, was subject to an unrest period with numerous earthquakes, beginning in December 2019. Using this abundant seismicity to produce tomographic images of the RP, we discovered a high $\mathrm{V}_{\mathrm{p}} / \mathrm{V}_{\mathrm{s}}$ anomaly below the volcanic system of Fagradalsfjall - the smallest of the 5 systems on the RP. This anomaly is clear on images as early as May 2020 and we interpret it as the top part of the source reservoir of the Fagradalsfjall Volcanic System, which now supplies magma to the eruption that started there on 19 March 2021.

From the tomographic images, we infer the roof of the reservoir at $\sim 10 \mathrm{~km}$ below the surface of the volcanic system, but it extends much deeper. We interpret the results as magma accumulation in the upper part of the reservoir at least by May 2020, and probably earlier, resulting in slight magma-pressure increase and doming of the reservoir roof. The associated stress changes in the roof triggered several earthquake swarms throughout 2020 and into early 2021.

Within the part of the roof closest to the reservoir (between 9-12 km depth) 40 earthquakes occurred during 2020. This number doubled again between 1 January and 19 March 2021, when the eruption began. We interpret the preceding earthquake swarm, which began on 24 February 2021 with an earthquake of M5.6, as being associated with the rupture of the roof of the reservoir and dike-segment injection. We interpret the increased activity on the 14th of March, and its location, as a second rupture and a new dike-segment injection which ultimately lead to the eruption, which is still on-going at the time of writing. The reservoir is the first one detected below any of the volcanic systems on the RP. Furthermore, the reservoir supplies magma to the first eruption on the RP for nearly 800 years and the first eruption in Fagradalsfjall for some 6000 years. 